\section{Gastro-retentive floating beads of curcumin $\beta$-cyclodextrin complex to treat stomach tumors}

\author{
Shishu Goindi, Kamalpreet Mann, \\ Nidhi Aggarwal \\ University Institute of Pharmaceutical \\ Sciences, Panjab University, Chandigarh, \\ India
}

\section{Abstract}

The aim of present study was to develop a multi-unit gastro-retentive floating dosage form of curcumin with targeted and sustained release characteristics. Although, protective effect of curcumin against inflammation and cancer is well documented, the clinical potential is underutilized owing to the physicochemical properties of the molecule which lead to poor oral bioavailability. Aqueous solubility of curcumin was enhanced by complex formation with $\beta$-cyclodextrin ( $\beta$-CD). This complex with enhanced solubility profile was further used to prepare multiple unit floating beads. Floating beads of curcumin $\beta$-cyclodextrin complex (FBCC) were prepared by dripping a mixture of sodium alginate and hydroxypropyl methylcellulose solution into calcium chloride solution acidified with acetic acid. FBCC were evaluated for percent drug entrapment, diameter, surface topography, buoyancy, in vitro release and pharmacodynamic activity against Benzo(a) pyrene $[\mathrm{B}(\mathrm{a}) \mathrm{P}]$ induced forestomach papillomas in albino female mice (Balb/C strain). The investigation revealed that floating beads possessed optimum formulation characteristics. The drug release from FBCC was fickian and sufficiently sustained for $12 \mathrm{~h}$. Results of antitumor studies against B(a)P induced neoplasia of forestomach suggests that the tumor incidence significantly reduced (50\%) using FBCC where as pure curcumin resulted in only $25 \%$ reduction. A multi-unit floating dosage form of curcumin $\beta$-CD complex possessing sustained release characteristics was developed for targeting gastric tumors. Results of in vitro studies and anti-tumor studies in animals suggest that FBCC can be safely and effectively used to treat neoplasia of stomach. However, these preliminary investigations warrant further pharmacokinetic studies and clinical evaluation in humans.

\section{Introduction}

The culinary and medicinal uses of turmer- ic, dried and powdered rhizomes of Curcuma longa $\mathrm{L}$. (Zingiberaceae), are well known and widely reported in the ancient Indian, Chinese and Japanese literature. ${ }^{1}$ Curcumin, [diferuloyl methane, (E,E)-1,7-Bis(4-hydroxy-3methoxyphenyl)-1,6-heptadiene-3,5-dione ] is a phyto-polyphenol orange-yellow pigment and the active constituent of turmeric. It is a crystalline compound having molecular weight of $368.37, \log P$ value of 2.92 and a melting point of $183^{\circ} \mathrm{C}$. Curcumin has been extensively investigated by various researchers across the globe for its potential therapeutic benefits. ${ }^{2}$ It is reported to possess anti-inflammatory, ${ }^{3}$ antioxidant, ${ }^{4}$ anticarcinogenic, ${ }^{5}$ antimutagenic, ${ }^{6}$ antiarthritic, ${ }^{7}$ antibacterial, ${ }^{8}$ antifungal, ${ }^{9}$ antiprotozoal, ${ }^{10}$ antiviral, 11 nephroprotective, 12 contraceptive, 13 anti-Alzheimer ${ }^{14}$ and anti-psoriatic ${ }^{15}$ activities.

Curcumin has been shown to enhance the effects of common anti-cancer drugs, and doses as high as 8 to $12 \mathrm{~g}$ per day have been shown to be well tolerated in humans. ${ }^{1}$ While all anticancer drugs weaken the immune system, curcumin enhances it and acts as an immune-restorer.16-18 Despite the considerable promise that curcumin is an efficacious and safe compound or more appropriately a panacea for all ills it has by no means been embraced by the formulation scientists. The main reason is that the compound is practically insoluble in water under acidic or neutral conditions. Although, soluble at alkaline $\mathrm{pH}$ but it undergoes rapid hydrolytic degradation to form feruloyl methane and ferulic acid. It is also metabolized in the liver particularly via glucuronidation and sulfation ${ }^{19}$ and these metabolites appear to lack any pharmacological activity. The initial reports by Wahlstorm and Blennow showed that after oral administration of $1 \mathrm{~g} / \mathrm{kg}$ curcumin to rats, more than $75 \%$ of curcumin was excreted in feces and negligible amount was detected in urine. ${ }^{20}$ Although, curcumin targets multiple chemotherapeutic and inflammatory pathways and has demonstrated safety and tolerability in humans ${ }^{21}$ however, the clinical literature lacks conclusive evidence supporting its use as a therapeutic agent due to its low bioavailability.

There have been several attempts to improve the solubility and bioavailability of curcumin by combining or complexing it with various macromolecules like gelatin, polysaccharides and cyclodextrins, ${ }^{22-24}$ solid dispersions with polyvinyl pyrrolidone, 25 aerosol delivery, ${ }^{26}$ prodrugs, ${ }^{27}$ liposomes, ${ }^{28}$ micelles and phoshoplipid complexes, ${ }^{29-31}$ microencapsulation, 32 PLGA nanoparticles, 33 solid lipid nanoparticles, 34 nanoemulsion, ${ }^{35}$ self microemulsifying system $^{36}$ and gastro-retentive tablets. 37

Taking into consideration the reasons attributable to poor bioavailability of curcumin, it would be advantageous to design a formulation
Correspondence: Shishu Goindi, University Institute of Pharmaceutical Sciences, Panjab University, Chandigarh-160014, India.

Tel: +91.172.2686257(R); +91.172.2534281 (0); Fax: +91.1762 .283000 .

E-mail: shishugoindi@yahoo.co.in; goindi@satyam.net.in

Key words: curcumin, curcumin $\beta$-cyclodextrin complex, calcium alginate beads, gastric residence time, benzo(a)pyrene.

Acknowledgements: the authors gratefully acknowledge the financial assistance from the University Grants Commission, New Delhi, India. Gift samples of Curcumin from Arjuna Natural Extracts Pvt. Ltd., Kerala, India, Carbopol 980 NF from Lubrizol Advanced Materials India Private Limited, Mumbai, India and HPMC by Colocron Asia Pvt. Ltd., Mumbai, India are gratefully acknowledged.

Conflict of interest: the authors report no conflicts of interest.

Received for publication: 21 July 2011 Accepted for publication: 7 September 2011.

This work is licensed under a Creative Commons Attribution NonCommercial 3.0 License (CC BYNC 3.0).

(C) Copyright S. Goindi et al., 2011

Licensee PAGEPress, Italy

Alternative Medicine Studies 2011; 1:e12

doi:10.4081/ams.2011.e12

system with enhanced solubility and oral bioavailability of curcumin. Besides enhancing the drug release the oral drug delivery system should also prolong the residence time of dosage form in stomach. Gastro-retentive drug delivery systems have been widely explored to achieve a prolonged and predictable drug delivery profile in the gastro-intestinal tract. These controlled release systems get retained in the stomach for longer period of time, thus helping in better and complete absorption of drug. A number of approaches have been used to increase gastric residence time by employing a variety of concepts like, bioadhesive systems, swellable polymers, density controlled delivery systems. Amongst these floating drug delivery systems are of great interest particularly the multiple unit floating dosage forms. These were designed keeping in view the all or nothing response of single unit floating dosage forms. ${ }^{38}$ Literature reports indicate widespread use of sodium alginate for achieving sustained release of drugs, ${ }^{39,40}$ targeting gastric mucosa ${ }^{41}$ and increasing the bioavailability of drugs. ${ }^{42}$ Sodium alginate has ability to form a stable and bioadhesive gel with calcium ions. ${ }^{4}$ Hydroxypropyl methylcellulose (HPMC) has been reported to enhance the sustained release 
properties of alginate by providing a denser inner matrix. ${ }^{44}$ Also, the preparative methodology of alginate beads involves the use of aqueous solvents, avoiding exposure of ingredients to high temperatures and toxic organic solvents. 45,46 Moreover, the resulting preparation is non-immunogenic, with bioadhesive properties that could offer an additional advantage in stomach targeting. Present work was designed to improve the aqueous solubility of curcumin by incorporating it into $\beta$-cyclodextrin $(\beta-C D)$ complex. Further to improve absorption of curcumin- $\beta$-CD complex from stomach, to target stomach tumors and to prevent degradation of curcumin the alkaline environment of intestine; floating beads were prepared. Floating beads of curcumin $\beta$-CD complex (FBCC) were characterized in vitro and evaluated for their protective potential against $\mathrm{B}(\mathrm{a}) \mathrm{P}$ induced gastric tumors in female Balb/C mice.

\section{Materials and Methods}

\section{Materials}

Curcumin was a gift from Arjuna Natural Extracts Pvt. Ltd., Kerala, India, Carbopol 980 NF was a gift from Lubrizol Advanced Materials India Private Limited, Mumbai, India and Hydroxypropyl methylcellulose (HPMC) K15M was a gift from Colorcon Asia Pvt Ltd., Mumbai, India. Sodium alginate was purchased from $\mathbf{s}$. d. Fine Chemicals Ltd., Mumbai, India. All other reagents and chemicals used were of analytical grade.

\section{Animals}

Albino female Balb/C mice 8 to 9 weeks old weighing 20 to $30 \mathrm{~g}$ were obtained from Central Animal House, Panjab University, Chandigarh, India and used for carrying out anti-tumor studies. Ethical approval to perform the aforementioned studies in female Balb/C mice was obtained from Panjab University, Institutional Animal Ethics Committee, Chandigarh India and their guidelines were followed throughout the studies (15/IAEC dated 04.09.2009).

\section{Validation of spectrophotometric method}

Various standards of curcumin ranging between 1-10 $\mu \mathrm{g} / \mathrm{mL}$ were prepared from 10 $\mu \mathrm{g} / \mathrm{mL}$ stock solution of curcumin in methanol and $\mathrm{HCl}$ buffer $\mathrm{pH}$ 1.2. The samples were analyzed using a UV-visible double beam spectrophotometer (Shimadzu, Kyoto, Japan) to prepare a calibration curve of curcumin at $\lambda_{\max }$ of 421 (methanol) and $430 \mathrm{~nm}$ ( $\mathrm{HCl}$ buffer $\mathrm{pH}$ 1.2). The methodology and data were validated for linearity, accuracy and precision.

\section{Preparation and evaluation \\ of curcumin $\beta-C D$ complex}

Kneading method was used to prepare 2:1 host-guest molecular complex of curcumin with $\beta$-CD which was confirmed by Fourier transform infra red (FT-IR) method (data not shown). ${ }^{23}$

\section{Preparation of floating beads}

$200 \mathrm{mg}$ of $\beta$-CD complex of curcumin was dissolved in $5 \mathrm{~mL}$ of distilled water. This solution was dispersed in sodium alginate solution (3\% w/v) containing HPMC K15M (alginate: $\mathrm{HPMC}=9: 1 \mathrm{w} / \mathrm{w})$. Then gas forming agent calcium carbonate $\left(\mathrm{CaCO}_{3}\right)$ was added to the solution in weight ratio $0.5: 1$ (gas forming agent: alginate $w / w)$. The mixture was degassed under bath sonicator (10-15 $\mathrm{min})$ to remove any entrapped air. The resulting solution was dropped through a $26 \mathrm{G}$ syringe needle into calcium chloride solution $(1 \% \mathrm{w} / \mathrm{v})$ containing $10 \% \mathrm{v} / \mathrm{v}$ acetic acid. 47 The beads were allowed to remain in calcium chloride $\left(\mathrm{CaCl}_{2}\right)$ solution for $2 \mathrm{~h}$ to improve the mechanical strength of the beads. The formed beads were separated, washed initially with ethanol and subsequently with distilled water and then freeze-dried. Blank beads without the curcumin complex were prepared using the same method. The formula used has been previously optimized for the various parameters like percent drug loading, drug entrapment efficiency, surface topography and buoyancy by optimizing the amounts of alginate, HPMC and $\mathrm{CaCO}_{3} .48$

\section{Characterization and evaluation of floating beads}

Determination of drug entrapment efficiency

An accurately weighed sample of FBCC (20 $\mathrm{mg}$ ) was crushed in a mortar and $10 \mathrm{~mL}$ of methanol was added. This mixture was transferred to a test tube and thoroughly mixed on a vortex and then centrifuged at $4200 \mathrm{rpm}$ for 30 min, filtered through $0.45 \mu$ membrane filter and analyzed spectrophotometrically at $\lambda_{\max }$ $421 \mathrm{~nm}$ against methanol as blank. Blank beads were treated similarly. Drug entrapment efficiency was calculated according to the following equation:

$$
\% \text { DEE }=\frac{\text { Actual drug content in beads }}{\text { Theoretical drug content }} \times 100
$$

\section{Determination of particle size}

The particle size and the size distribution of FBCC were determined in the dry state using the optical microscopy method. The mean surface diameter was calculated arithmetically, using optical microscope fitted with an ocular micrometer and stage micrometer. Approximately, 400 beads were analyzed for their size and mean diameter was calculated using Edmundson's equation. ${ }^{49}$

\section{Surface characterization by scanning electron microscopy}

The external and cross-sectional morphology of FBCC was characterized by scanning electron microscope (SEM). Samples were coated with gold film under vacuum to modify in conducting materials and investigated. The internal structure of the beads was examined by cutting them half with a steel blade.

\section{In vitro evaluation}

Floating and dissolution characteristics of beads were evaluated using USP Type II apparatus filled with $900 \mathrm{~mL} \mathrm{HCl}$ buffer $\mathrm{pH} 1.2$, maintained at $37 \pm 0.5^{\circ} \mathrm{C}$ and stirred at $50 \mathrm{rpm}$. At different time intervals, a $5 \mathrm{~mL}$ aliquot of the sample was withdrawn and the volume was replaced with an equivalent amount of fresh dissolution medium kept at $37^{\circ} \mathrm{C}$. The collected samples were filtered using $0.45 \mu$ membrane filter and analyzed at $\lambda_{\max } 430 \mathrm{~nm}$ using a UVvisible spectrophotometer against $\mathrm{HCl}$ buffer pH 1.2 taken as blank. Drug release data were corrected for the values of the drug loss during sampling. Similarly, dissolution studies with placebo beads, pure curcumin and $\beta-\mathrm{CD}$ complex of curcumin were also performed.

The absorbance data obtained was processed applying correction factor for volume and drug loss during sampling using the following equation:

$$
\mathrm{C}_{\mathrm{i}}=\mathrm{A}_{\mathrm{i}}+\left(\mathrm{V}_{\mathrm{s}} / \mathrm{V}_{\mathrm{t}}\right) \times \sum_{i=1}^{n-1} A_{i}\left[V_{i} /\left(V_{i}-V_{s}\right]\right.
$$

where, $\mathrm{C}_{\mathrm{i}}=$ Conc. of drug dissolved; $A_{i}=$ Absorbance; $V_{s}=$ Volume of sample withdrawn; $V_{t}=$ Total volume of buffer in dissolution basket.

The values of fraction of drug dissolved, mean percent drug dissolved along with standard deviation at varied times were calculated using Microsoft Office Excel 2007.

The time between the introduction of the FBCC into the medium and its buoyancy to the upper one third of the dissolution vessel (buoyancy lag time) and the time for which the beads constantly floated (duration of buoyancy) were measured simultaneously as a part of dissolution studies. 47

\section{Anti-tumor activity}

Albino female mice (Balb/C strain) aged 8 to 9 weeks old weighing 20 to $30 \mathrm{~g}$ was used. The animals were kept under a standard 12/12 light/dark cycle and were given food and water ad libitum. The animals were administered 2 doses of $3 \mathrm{mg}$ of benzo(a)pyrene [B(a)P] in $0.25 \mathrm{~mL}$ of corn oil orally with 2 weeks between doses. Placebo floating beads alone were administered to the control group. ${ }^{50}$ The $\mathrm{B}(\mathrm{a}) \mathrm{P}$ treated mice were divided into 3 groups 
$(n=10)$ : pure curcumin treatment, FBCC treatment and no treatment. The treatment groups were administered $75 \mathrm{mg} / \mathrm{kg}$ of the drug in a corn oil suspension or equivalent (in the case of FBCC) orally for 5 consecutive days followed by 2 drug-free days. The dosage regimen was repeated till the end of the experiment. ${ }^{50}$

\section{Tumor determination}

Animals were sacrificed by cervical dislocation 18 weeks after the last dose of $\mathrm{B}(\mathrm{a}) \mathrm{P}$. The forestomach was separated and was cut longitudinally and fixed in $10 \%$ buffered formalinphosphate. Stomach papillomas measuring 1.0 mm or larger were counted using a magnifying glass. ${ }^{50,51}$ The relative susceptibility to $\mathrm{B}(\mathrm{a}) \mathrm{P}$ induced tumors was expressed by the tumorigenic index as proposed by Shimkin. 52

Tumorigenic Index=prcentage of mice with tumors $\mathrm{X}$ mean number of tumors per tumor bearing mouse

All the data was statistically analyzed by one way analysis of variance followed by Dunnett's method. $\mathrm{P}<0.05$ was considered significant.

\section{Results and Discussion}

\section{Validation of spectrophotometric method}

The linearity range for curcumin in methanol and $\mathrm{HCl}$ buffer $\mathrm{pH} 1.2$ was found to be $1-10 \mu \mathrm{g} / \mathrm{mL}(\mathrm{r} 2=0.9999)$. The equation for linearity for methanol was observed to be $\mathrm{y}=$ $1.45 \mathrm{E}$ - $01 \mathrm{x}$ with $\mathrm{E} 1 \% 1 \mathrm{~cm}=1450$ at $\lambda_{\max } 421$ $\mathrm{nm}$. The equation for linearity for $\mathrm{HCl}$ buffer $\mathrm{pH} 1.2$ was observed to be $\mathrm{y}=5.40 \mathrm{E}-02 \mathrm{x}$ with $\mathrm{E} 1 \% 1 \mathrm{~cm}=540$ at $\lambda_{\max } 430 \mathrm{~nm}$.

\section{Drug entrapment efficiency}

The entrapment efficiency of curcumin in FBCC was found to be $66.42 \%$.

\section{Particle size analysis and surface and cross sectional morphology}

The mean surface diameter of FBCC was observed to be $1.68 \pm 0.07 \mathrm{~mm}$. The surface and cross-sectional SEM images for FBCC are shown in Figure 1. FBCC appeared to be almost spherical in shape with wrinkled surface which may be attributed to the release of carbon dioxide from the surface of beads during formation. The cross sectional view of the beads revealed many pores in the alginate gel matrix that might contribute to floating characteristics of beads.

\section{In vitro evaluation}

Floating properties

The floating ability of FBCC was evaluated along with dissolution studies. The beads showed instantaneous and excellent floating ability (almost 100\%) which persisted nearly for $24 \mathrm{~h}$.

\section{In vitro dissolution studies}

The comparative results of the dissolution studies of pure curcumin, $\beta$-CD complex of curcumin and FBCC are depicted in Figure 2. A very low percent drug release of $1 \%$ from pure curcumin in $24 \mathrm{~h}$ indicates the poor solubility characteristics of curcumin at the gastric $\mathrm{pH}$. The rate of drug release (flux) for pure curcumin for first $3 \mathrm{~h}$ was observed to be 14.55 $\mu \mathrm{g} / \mathrm{h}$. However, inclusion of curcumin into $\beta$ CD drastically improved the solubility of curcumin in the acidic environment ${ }^{23}$ and this is apparent from the release pattern of $\beta$-CD complex of curcumin (Figure 2). Almost 50\% of curcumin was released in $30 \mathrm{~min}$ and nearly $80 \%$ was released in $2 \mathrm{~h}$ from $\beta$-CD complex of curcumin. As evident from the graph, curcumin $\beta-C D$ complex possessed a substantially high flux rate amounting to $380.18 \mu \mathrm{g} / \mathrm{h}$ for first $3 \mathrm{~h}$. This burst release of curcumin got sustained when the complex was incorporated in FBCC. In case of $\beta$-CD complex of curcumin almost complete release was seen in $3 \mathrm{~h}$ but in FBCC only $50 \%$ of curcumin released from the beads in $5 \mathrm{~h}$ and $90 \%$ curcumin was released in $12 \mathrm{~h}$. The rate of curcumin release from floating beads for first $3 \mathrm{~h}$ was found to be 185.43 $\mu \mathrm{g} / \mathrm{h}$.

When the dissolution data of FBCC was sub-
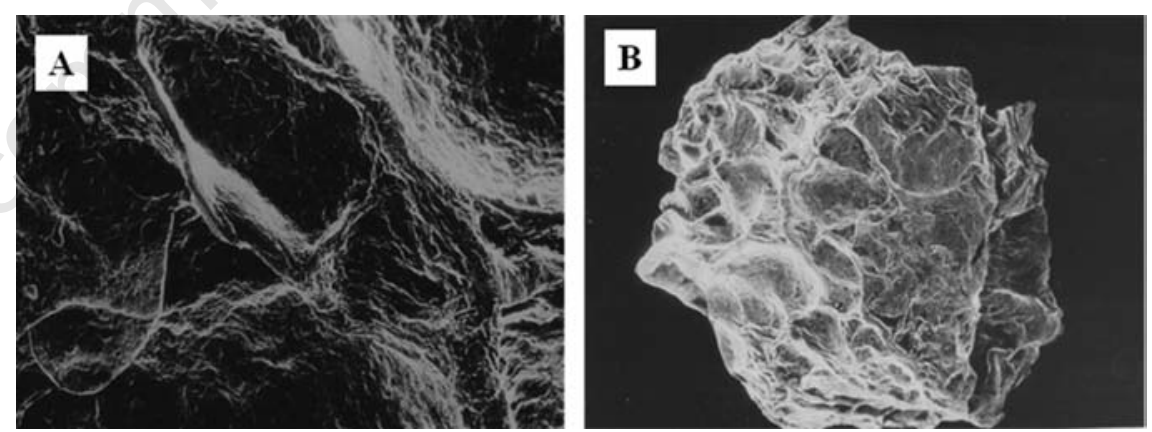

Figure 1. Scanning electron photomicrograph of floating bead of curcumin (A) surface view (B) cross section.

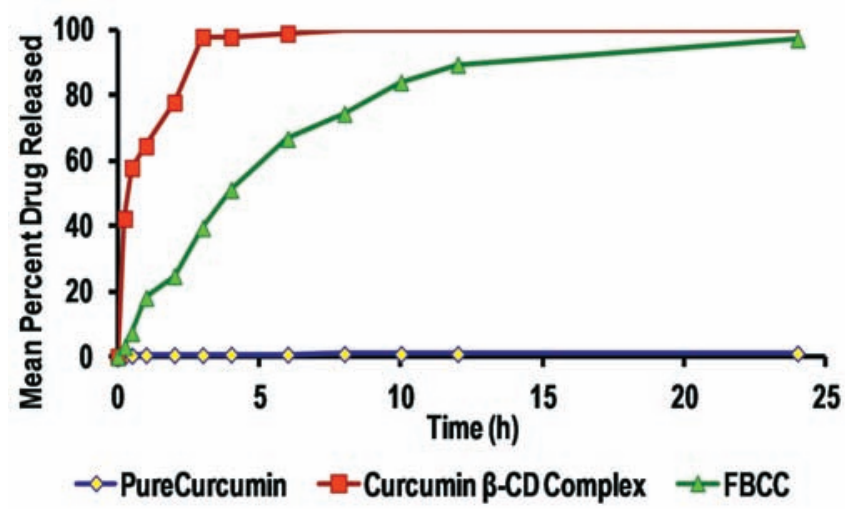

Figure 2. Comparison of dissolution profile of curcumin from different systems. jected to kinetic model fitting it was observed to follow First Order Kinetics with highest linearity $\left(r^{2}=0.9934\right)$ via Fickian diffusion $(\mathrm{n}=0.43)$. First Order Model describes release from systems where drug release rate is concentration dependent. However, the drug release was also found to be close to Koremeyer-Peppas Kinetics $\left(\mathrm{r}^{2}=0.9826\right)$ which describes the release of drugs from a swellable system as a square root of time dependent solution results revealed that the entrapment of curcumin $\beta-C D$ complex in alginate beads not only resulted in improved dissolution as compared to pure curcumin but also sustained the release of curcumin.

\section{Anti-tumorigenic effects}

After obtaining encouraging results of the in vitro dissolution studies of FBCC, further invivo pharmacodynamic studies were perdeveloped multiple unit floating dosage per o examine the anticancer activities of therapeutic agents against gastro-intestinal cancers. The studies indicate that treatment of mice with $\mathrm{B}(\mathrm{a}) \mathrm{P}$ resulted in $100 \%$ incidence of forestomach tumors after 10 weeks with an of 1.75 tumors per mouse compared to control group; fed with placebo floating beads (Figure 3). Treatment of mice with pure curformed to evaluate the therapeutic efficacy of 
cumin after the last dose of B(a)P (i.e., during the initiation period) resulted in only $25 \%$ reduction in tumor incidence (percentage of number of mice with tumors). A lower reduction in tumor incidence in animal group treated with pure curcumin may be attributed to the low solubility of curcumin in acidic $\mathrm{pH}$ of stomach, which might have prevented its solubilization in gastric fluids. ${ }^{24}$ However treatment with $\mathrm{FBCC}$ resulted in 50\% reduction in tumor incidence. Number of tumors per tumor-bearing mouse was reduced to $71.42 \%$ and $38.29 \%$, with pure curcumin and floating beads respectively. Similarly, the tumorigenic index (product of percentage of mice with tumors and number of tumor bearing mouse) was reduced to 93.75 and 33.5 with pure curcumin and floating beads respectively. The statistically significant $(\mathrm{P}<0.05)$ reduction in the number of mice with tumors was obtained with floating beads as compared with pure curcumin treatment suggest the higher bioavailability and better therapeutic efficacy of floating beads.

\section{Discussion}

The present study was performed to enhance the solubility of curcumin at gastric $\mathrm{pH}$ and then prepare a floating dosage form to increase its gastric residence time. Solubility was improved by preparing $\beta$-CD complex of curcumin. $\beta$-CD was selected for encapsulation of curcumin because it is a semi-natural product with extremely low toxicity and reported to enhance solubility of curcumin. ${ }^{23,24}$ Literature reports reveal that supramolecular chemistry of $\beta$-CD offers water soluble inclusion complexes with different drug molecules. Cyclodextrins are reported to possess hydrophilic exterior and a lipophilic core in which the appropriately sized organic molecules can form non-covalent inclusion complexes resulting in increased aqueous solubility and chemical stability. ${ }^{54} \beta$-CD complex of curcumin possessed very high solubility as compared to pure drug which is evident from dissolution profile (Figure 2).

Curcumin $\beta$-CD complex was used to prepare FBCC by using a combination of polymers. The drug release from FBCC was sustained over a period of $12 \mathrm{~h}$ which may be owed to the presence of alginate and HPMC mesh network in the beads which could have restricted the diffusion of the embedded drug, leading to an extended period of drug delivery. Also, the floating nature of the FBCC might have prolonged its gastric residence time. Therefore, the presence of porous polymer network might have served as a stabilizer, which not only controlled the release but also lengthened the stay of FBCC in stomach improving the therapeutic activity of curcumin. .55

The in vivo studies in Balb/C mice treated with $\mathrm{B}(\mathrm{a}) \mathrm{P}$ also confirmed the therapeutic efficacy of floating bead dosage form of curcumin $\beta$-CD when compared with pure curcumin. The low activity of pure curcumin may be explained on the basis of poor solubility of curcumin in gastric contents and low gastric residence along with degradation in alkaline conditions of intestine affecting its overall therapeutic performance. Whereas, the floating beads were expected to stay in the stomach for a much longer period of time and produce a more efficient local effect. Moreover, $\beta$-CD complex of curcumin improved solubility of curcumin and floating beads provided site-specific delivery to the gastric tumors resulting in significant therapeutic effect.

\section{Conclusions}

In the present work floating beads of curcumin $\beta$-CD complex were formulated to provide sustained release of drug with an aim to provide an effective therapy with enhanced solubility and bioavailability; targeted action and better absorption to treat stomach tumors. FBCC exhibited sustained release of curcumin with excellent floating properties. Also, in vivo antitumor studies confirmed that the overall rate of tumor incidence and number of

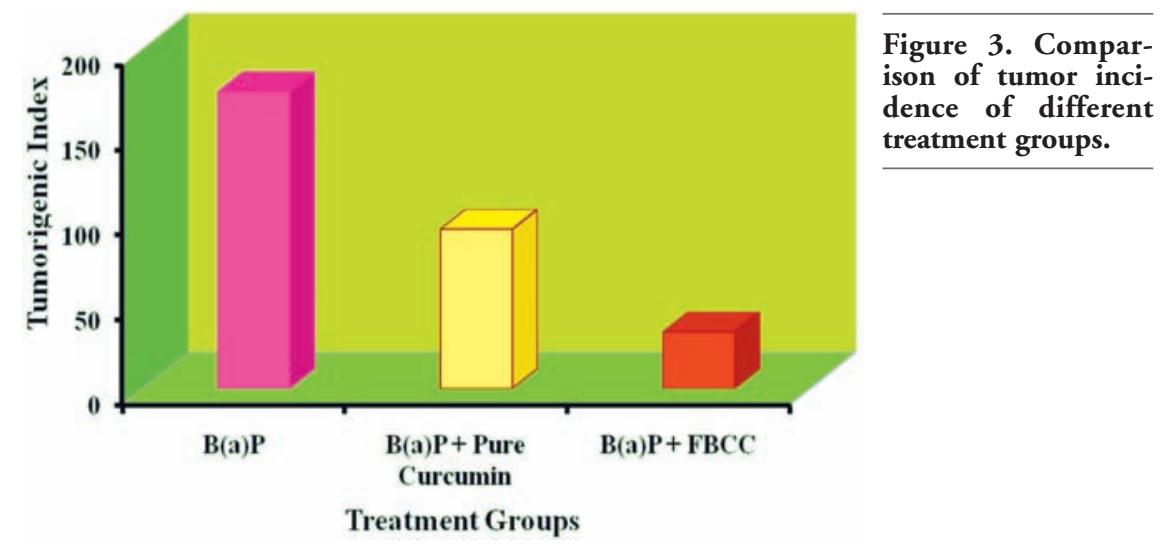

Figure 3. Comparison of tumor incidence of different treatment groups.

tumors/mouse is less in animal group treated with FBCC compared to animals treated with pure curcumin in $\mathrm{B}(\mathrm{a}) \mathrm{P}$ induced tumor model of mice. These observations point to the potential of gastro-retentive form of curcumin $\beta$-CD complex as an effective delivery system to treat stomach tumors in animals and possibly in humans as well.

\section{References}

1. Goel A, Aggarwal BB. Curcumin, the golden spice from Indian saffron, is a chemosensitizer and radiosensitizer for tumors and chemoprotector and radioprotector for normal organs. Nutr Cancer 2010;62:919-30.

2. Hatcher H, Planalp R, Cho J, et al. Curcumin: from ancient medicine to current clinical trials. Cell Mol Life Sci 2008;65:1631-52.

3. Chen D, Nie M, Fan M, Bian Z. AntiInflammatory activity of curcumin in macrophages stimulated by lipopolysaccharides from Porphyromonas gingivalis. Pharmacology 2008;82:264-9.

4. Sandur SK, Pandey MK, Sung B, et al. Curcumin, demethoxycurcumin, bisdemethoxycurcumin, tetrahydrocurcumin and turmerones differentially regulate antiinflammatory and antiproliferative responses through a ROS-independent mechanism. Carcinogenesis 2007;28: 1765-73.

5. Johnson JJ, Mukhtar H. Curcumin for chemoprevention of colon cancer. Cancer Lett 2007;255:170-81.

6. Shukla Y, Arora A, Taneja P. Anti-mutagenic potential of curcumin on chromosomal aberrations in Wistar rats. Mutat Res 2002;515:197-202.

7. Funk JL, Oyarzo JN, Frye JB, et al. Turmeric extracts containing curcuminoids prevent experimental rheumatoid arthritis. J Nat Prod 2006;69;351-5.

8. Mishra S, Narian U, Mishra R, Misra K. Design, development and synthesis of mixed bioconjugates of piperic acid-glycine, curcumin-glycine / alanine and curcuminglycine-piperic acid and their antibacterial and antifungal properties. Bioorg Med Chem 2005;13:1477-86.

9. Wuthi-Udomler MW, Luanratana G0, Caichompoo W. South East Asian. J Tropical Med Public Health 2000;31 Suppl 1:178-82.

10. Koide T, Nose M, Ogihara $\mathrm{Y}$, et al. Leishmanicidal effect of curcumin in vitro. Biol Pharmacol Bull 2002;25:131-3.

11. Taher MM, Lammering G, Hershey C, Valerie K. Curcumin inhibits ultraviolet light induced human immunodeficiency virus gene expression. Mol Cell Biochem 2003;254:289-97.

12. Cekmen M, Ilbey YO, Ozbek E, et al. Curcumin prevents oxidative renal damage 
induced by acetaminophen in rats. Food Chem Toxicol 2009;47:1480-4.

13. Naz RK. Can curcumin provide an ideal contraceptive? Mol Reprod Dev 2011;78:116-23.

14. Hamaguchi T, Ono K, Yamada M. Curcumin and alzheimer's disease. CNS Neurosci Ther 2010;16:285-97.

15. Shishodia S, Sethi G, Aggarwal BB. Curcumin: Getting back to the roots. NY Academic Sci 2005;1056:206-17.

16. Bhattacharyya S, Mandal D, Saha B. Curcumin prevents tumor-induced apoptosis through Stat-5a-mediated Bcl-2 induction. J Biol Chem 2007;282:15954-64.

17. Bhattacharyya S, Mandal D, Sen GS, et al. Tumor-induced oxidative stress perturbs nuclear factor-kappaB activity-augmenting tumor necrosis factor-alpha-mediated T-cell death: Protection by curcumin. Cancer Res 2007;67:362-70.

18. Kurup VP, Barrios CS, Raju R, et al. Immune response modulation by curcumin in a latex allergy model. Clin Mol Allergy 2007;5:1-12.

19. Christopher R, Ireson D, Jones J, et al. Metabolism of the cancer chemopreventive agent curcumin in human and rat intestine. Cancer Epidemiol Biomarkers Prev 2002;11:105-11.

20. Wahlstrom B, Blennow G. A study on the fate of curcumin in the rat. Acta Pharmcol Toxicol 1978;43:86-92.

21. Goel A, Jhurani S, Aggarwal BB. Multi-targeted therapy by curcumin: how spicy is it? Mol Nutr Food Res 2008;52:1010-30.

22. Loftsson T, Sigurdsson HH, Masson M, Schipper N. Preparation of solid drug/cyclodextrin complexes of acidic and basic drugs. Pharmazie 2004;59:25-9.

23. Tang B, Ma L, Wang HY, Zhang GY. Study on the supramolecular interaction of curcumin and beta-cyclodextrin by spectrophotometry and its analytical application. J Agric Food Chem 2002;50:1355-61.

24. Tonnesen HH, Masson M, Loftsson T. Studies of curcumin and curcuminoids. XXVII. Cyclodextrin complexation: solubility, chemical and photochemical stability. Int J Pharm 2002;244:127-35.

25. Paradkar A, Ambike AA, Jadhav BK, Mahadik KR. Characterization of curcumin-PVP solid dispersion obtained by spray drying. Int $\mathrm{J}$ Pharm 2004;271:281-6.

26. Aggarwal BB, Knight JV. Aerosol delivery of curcumin. Patent US 20050181036, 2005 Aug 18.

27. Lu P, Tong Q, Jiang F, et al. Preparation of curcumin prodrugs and their in vitro antitumor activities. J Huazhong Univ Sci Technolog Med Sci 2005;25:732-4.

28. Kurzrock R, Li L, Mehta K, Aggarawal BB. Liposomal curcumin for treatment of cancer, Patent US 20060067998, 2006 March 30.

29. Maiti K, Mukherjee K, Gantait A, et al. Curcumin-phospholipid complex: prepara- tion, therapeutic evaluation and pharmacokinetic study in rats. Int $\mathrm{J}$ Pharm 2007;330:155-63.

30. Marczylo TH, Verschoyle RD, Cooke DN, et al. Comparison of systemic availability of curcumin with that of curcumin formulated with phosphatidylcholine. Cancer Chemother Pharmacol 2007;60:171-7.

31. Liu A, Lou H, Zhao L, Fan P. Validated LC/MS/MS assay for curcumin and tetrahydrocurcumin in rat plasma and application to pharmacokinetic study of phospholipid complex of curcumin. J Pharm Biomed Anal 2006;40:72-7.

32. Aziz HA, Peh KK, Tan YTF. Solubility of core materials in aqueous polymeric solution effect on microencapsulation of curcumin. Drug Dev Ind Pharm 2007;33:1263-72.

33. Anand P, Nair HB, Sung B, et al. Design of curcumin-loaded PLGA nanoparticles formulation with enhanced cellular uptake, and increased bioactivity in vitro and superiorbioavailability in vivo. Biochem Pharmacol 2010;79:330-8.

34. Yadav V, Devi K, Yadav S, Sarasija S. Novel formulation of solid lipid microparticles of curcumin for anti-angiogenic and antiinflammatory activity for optimization of therapy of inflammatory bowel disease. $\mathrm{J}$ Pharm Pharmacol 2009;61:311-21.

35. Wang X, Jiang Y, Wang Y, et al. Enhancing anti-inflammation activity of curcumin through O/W nanoemulsions. Food Chem 2008;108:419-24.

36. Cui J, Yu B, Zhao Y, et al. Enhancement of oral absorption of curcumin by selfmicroemulsifying drug delivery systems. Int J Pharm 2009;371:148-55.

37. Shishu, Gupta N, Aggarwal N. Bioavailability Enhancement and Targeting of Stomach Tumors Using Gastro-Retentive Floating Drug Delivery System of Curcumin-“A Technical Note". AAPS PharmSciTech 2008;9:810-3.

38. Ichikawa M, Watanabe S, Miyake Y. A new multiple-unit oral floating dosage form, I: preparation and evaluation of floating and sustained release characteristics. J Pharm Sci 1991;80:1062-6.

39. Badwan AA, Abumalooh A, Sallam E, et al. A sustained release drug delivery system using calcium alginate beads. Drug Dev Ind Pharm 1985;11:239-56.

40. Shiraishi S, Imai T, Otagiri M. Controlled release preparation of indomethacin using calcium alginate gel. Biol Pharm Bull 1993;16:1164-8.

41. Murata Y, Kofuji K, Kawashima S. Preparation of floating alginate beads for drug delivery to gastric mucosa. J Biomater Sci Polym Ed 2003;14:581-8.

42. Stops F, Fell JT, Collett JH, et al. Citric acid prolongs the gastro-retention of a floating dosage form and increases bioavailability of riboflavin in the fasted state. Int $\mathrm{J}$ Pharm 2006;308:14-24.

43. Tønnesen HH, Karlsen J. Alginate in drug delivery systems. Drug Dev Ind Pharm 2002;28:621-30.

44. Giunchedi P, Gavini E, Moretti MDL, Pirisino G. Evaluation of alginate compressed matrices as prolonged drug delivery systems. AAPS PharmSciTech 2000;1:E19.

45. Halder A, Mukherjee S, Sa B. Development and evaluation of polyethyleneimine-treated calcium alginate beads for sustained release of diltiazem. J Microencapsul 2005;22:67-80.

46. Streubel A, Siepmann J, Bodmeier R. Multiple unit gastroretentive drug delivery systems: a new preparation method for low density microparticles. J Microencapsul 2003;20:329-47.

47. Choi BY, Park HJ, Hwang SJ, Park JB. Preparation of alginate beads for floating drug delivery system: effects of $\mathrm{CO} 2$ gasforming agents. Int J Pharm 2002;239:81-91.

48. Shishu, Gupta N, Aggarwal N. Stomach Specific Drug Delivery of 5-Fluorouracil Using Floating Alginate Beads. AAPS PharmSciTech 2007;8:Article 48.

49. Sinko PJ, editor. Micromeritics. In: Martin's Physical Pharmacy and Pharmaceutical Sciences. Philadelphia: Lippincott Williams \& Wilkins; 2007. pp. 533-60.

50. Triano A, Simpson JB, Krathy M, et al. Protective effects of trifluralin on benzo(a)pyrene-induced tumors in $\mathrm{A} / \mathrm{J}$ mice. Cancer Res 1985;45:601-7.

51. Deshpande SS, Ingle AD, Maris GB. Inhibitory effects of curcumin-free aqueous turmeric extract on benzo(a)pyrene-induced forestomach papillomas in mice. Cancer Lett 1999;118:79-85.

52. Shimkin MB. Induced pulmonary tumors in mice. II. Reaction of lung of strain A mice to carcinogenic hydrocarbons. Arch Pathol 1940;29:239-55.

53. Jackson C, Ofoefule $\mathrm{S}$. Use of Xanthan gum and ethylcellulose in formulation of metronidazole for colon delivery. J Chem Pharm Res 2011;3:11-20.

54. Loftsson T, Brewster M.E. Pharmaceutical applications of cyclodextrins and drug solubilization and stabilization. J Pharm Sci, 1996;85:1017-25.

55. Colombo P, Santi P, Bettini R, et al. Drug release from swelling controlled systems, Part-II Mechanism based classification of controlled release devices. In: Wise DL, editor. Handbook of Pharmaceutical Controlled release Technology. New York: Marcel Decker, Inc.; 2008. pp. 183-210. 